Composites Part B: Engineering

November 2011, Volume 153, Pages 256-263

http://dx.doi.org/10.1016/i.compositesb.2018.07.028

http://archimer.ifremer.fr/doc/00450/56197/

(c) 2018 Published by Elsevier Ltd.

\title{
Impact of fillers (short glass fibers and rubber) on the hydrolysis-induced embrittlement of polyamide 6.6
}

Le Gac Pierre-Yves ${ }^{1,{ }^{*}}$, Fayolle Bruno ${ }^{2}$

\author{
${ }^{1}$ Marine Structures Laboratory, IFREMER Bretagne Centre, Plouzané, France \\ ${ }^{2}$ Laboratory PIMM, Ensam, CNRS, Cnam, 151 boulevard de l'Hôpital, Paris, France \\ * Corresponding author : Pierre-Yves Le Gac, email address : $\underline{\text { Pierre.Yves.Le.Gac@ifremer.fr }}$
}

\begin{abstract}
:
This study deals with the durability of composites based on polyamide 6.6 (PA6.6) in a humid environment, and more especially, with the loss of fracture properties. It is known that PA6.6 undergoes plasticization in the presence of water, but hydrolysis also occurs. This hydrolysis leads to a sharp decline in fracture properties in resin. The aim of this study is thus to understand the behavior of two PA6.6-based composites, one containing short glass fibers and the other both glass fibers and a rubber. The results showed the transition from ductile to brittle behavior as a function of hydrolysis time in resin. For composites, the drop in elongation breaking with the macromolecular chain length was linear for all ageing conditions considered here without marked transition. The results presented here can be used for lifetime prediction of PA6.6-based composites in a humid environment.
\end{abstract}

Keywords : Polyamide 6.6, Hydrolysis, Fracture, Embrittlement, Reinforced plastics 


\section{Introduction}

Polyamide-based composites are widely used in many industries, because of their intrinsic properties such as the ease of process. In addition, the fact that resin is a thermoplastic material gives it a very interesting recycling potential. Lastly, these materials are cheap compared to other thermoplastic matrices such as PEEK and PEI. Nevertheless, despite all these advantages, the use of polyamide 6-6 (PA6.6) composites is today limited on account of their durability, which remains poorly understood. It is evident that PA6.6 and, a fortiori, PA6.6 composites are very sensitive to the environment whether in terms of oxidative degradation [1-3] or interaction with water $[4,5]$. We will focus here on the effect of water.

When PA6.6 is subjected to a humid environment, it undergoes two main types of degradation. First, a physical and reversible degradation is induced by the large absorption of water in the amorphous phase of PA6.6. This degradation known as plasticization leads to a sharp increase in the mobility of macromolecular chains, resulting in a strong decrease in $\mathrm{T}_{\mathrm{g}}$ (from $60^{\circ} \mathrm{C}$ to $-20^{\circ} \mathrm{C}$ ). A drop in mechanical properties such as stiffness and yield stress also occurs. Simultaneously, an increase in strain at break can be observed $[6,7]$.

The second degradation induced by the presence of water is the hydrolysis of amide groups in the resin [8]. This chemical degradation is irreversible and also results in a strong modification of mechanical properties. In fact, hydrolysis causes a cleavage of the macromolecular chains over time, which leads to the embrittlement of the polymer. It was previously shown that polymers have a critical molar mass $\left(\mathrm{M}^{\prime} \mathrm{c}\right)$ below 
which the material has a brittle character, whereas its behavior is ductile above $\mathrm{M}^{\prime} \mathrm{C}$ [9]. The hydrolysis of materials, which leads to a chain break and thus a decrease in the molar mass, therefore results in a ductile/brittle transition of the materials.

Short glass fibers are often used in PA6.6-based composites to increase material stiffness [10], increase fracture toughness or fatigue life $[11,12]$, and even reduce the cost of the material. An addition of rubber particles has been as well as proposed to improve impact fracture properties [13]. This type of PA6.6-based composite is now widely used, although the addition of short fiberglass and/or elastomers in resins could affect the durability of such material in a humid environment. This study therefore deals with the impact of the composition of two PA6.6-based composites that contain short glass fibers with and without rubber. For each step of the study, the polyamide alone, the composite with only fiberglass, and the complete composite are considered in order to understand the impact of composition on the embrittlement induced by the hydrolysis of the matrix. Two causes can lead to modifying the embrittlement time for a given exposure condition. One the one hand, the filler can modify the hydrolysis kinetic, and on the other, it can quantitatively change the structure-property relationship in terms of the chain scission number required to embrittle the composite.

First, we will detail the experimental conditions with a description of the materials considered herein as well as the ageing conditions and characterization. The experimental results will then be presented considering water absorption, chain scission in PA6.6 through molar mass measurements, and finally tensile properties in 
both wet and dry states. Based on these experimental results, the impact of fillers in the PA6.6 matrix on hydrolysis-induced embrittlement will be discussed.

\section{Materials and methods}

\subsection{Materials and ageing procedures}

Three types of polymer composites are considered in this study: an unfilled PA6.6 polymer, a PA6.6 composite with $35 \%$ by weight of short glass fibers, and a PA6.6 composite filled with $25 \%$ by weight of short glass fibers and rubber. To assess rubber content while considering that rubber is hydrophobic, mass at equilibrium for some water activities (relative humidities) was measured by dynamic vapor sorption (DVS) for the composites with and without rubber particles. Water absorption as a function of water activity is reported in Figure 1. The shape of this curve has been discussed in detail in [14]. Given that crystallinity is similar between both composites, we can attribute the observed discrepancy to the rubber fraction. According to this hypothesis, the rubber content is thus close to $23 \%$. 


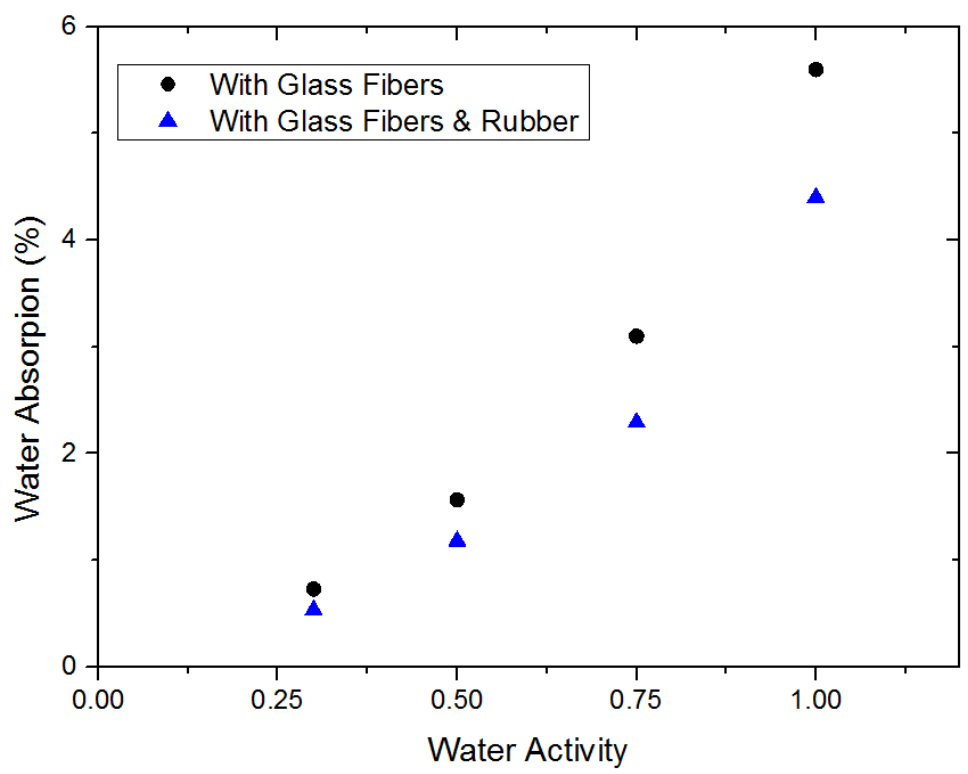

Figure 1: Water absorption as a function of water activity at $40^{\circ} \mathrm{C}$

The main characteristics of these materials are reported in Table 1. Furthermore, we did not observe a significant influence of fillers on the matrix in terms of crystallinity measured by DSC (See Table 1). As a result, we will hereafter consider crystallinity to be similar for all materials studied. 


\begin{tabular}{l|c|c|c} 
Type of polymer & $\begin{array}{c}\text { Glass fiber } \\
\text { content }\end{array}$ & $\begin{array}{c}\text { Rubber content } \\
\text { (\% in mass) }\end{array}$ & $\begin{array}{c}\text { Matrix crystallinity } \\
\text { content }\end{array}$ \\
& 0 & 0 & 39 \\
\hline PA6.6 & 25 & 0 & 36 \\
\hline Composite (glass & & & \\
fiber) & 25 & 23 & 37 \\
\hline Composite (glass & &
\end{tabular}

Table 1: Main characteristics in terms of the composition of the three considered materials

The samples of the three materials were immersed in deionized water at $40^{\circ} \mathrm{C}, 60^{\circ} \mathrm{C}$, and $80^{\circ} \mathrm{C}$. The water temperature was regulated with an accuracy of $1^{\circ} \mathrm{C}$, and a continuous renewal was carried out to avoid any water contamination. Before the tests, samples were kept immersed to prevent water evaporation. All samples were dried prior to ageing. Lastly, the chosen sample thickness was below $2 \mathrm{~mm}$ to ensure a homogenous degradation through the sample thickness. Hydrolysis degradation was characterized for the exposures at $60^{\circ} \mathrm{C}$ and $80^{\circ} \mathrm{C}$, since it has been recognized that this mechanism is predominant over oxidation if the exposure temperature exceeds $50^{\circ} \mathrm{C}$ in immersion [15].

The drying, performed before and, in some cases, after ageing, was conducted in a controlled enclosure at $40^{\circ} \mathrm{C}+/-1^{\circ} \mathrm{C}$ with humidity equal to $0 \mathrm{RH}$. The drying was carried out until a stable mass was obtained. Under these conditions, during drying, there was no reversion of the phenomenon of hydrolysis of the polyamide [6]. 


\subsection{Mass variation}

Mass variation during ageing was performed on previously dried square samples with $50 \mathrm{~mm}$ length and $2 \mathrm{~mm}$ thickness. For each test condition, three samples were used. These samples were regularly weighed with a Startorius ED124S balance with an accuracy of $0.1 \mathrm{mg}$. Before being weighed, the outer surface of the samples was wiped with absorbent paper. Mass variations were calculated using the following equation:

$$
\Delta m=\frac{m_{(t)}-m_{o}}{m_{o}} * 100
$$

Where $\Delta \mathrm{m}$ is the mass variation in $\%, \mathrm{~m}_{(\mathrm{t})}$ is the sample mass at a specific time $\mathrm{t}$ in $\mathrm{g}$, and $m_{0}$ is the initial mass of the sample in $g$.

\subsection{Tensile test}

Tensile tests were performed on a $10 \mathrm{kN}$ Instron machine in a room regulated at $21^{\circ} \mathrm{C}$ $+/-1^{\circ} \mathrm{C}$ and $50 \%$ humidity. Characterizations were made according to ISO 537 with sample type B1. Three specimens were tested under these conditions in order to obtain an average and standard deviation. Tensile behavior is represented in nominal stress (MPa) versus nominal stress that is without unity (i.e. $\mathrm{mm} / \mathrm{mm}$ ). When considering changes during ageing, strain at break is considered in \% because it is widely used for end of life criteria.

\subsection{SEC measurement}


Molar mass was determined by SEC made by the PeakExpert Company according to the Laun and al. method [16] and used in [17]. Samples of $25 \mathrm{mg}$ were dissolved in $10 \mathrm{ml}$ of 1,1,1,3,3,3-hexafluoroisopropan-2-ol (HFiP), with the dissolution being performed for $24 \mathrm{~h}$ at room temperature. Samples were injected in the chromatograph (Waters 2695) after filtration on PTFE $0.2 \mu \mathrm{m}$. The separation was performed using a pre-column and two columns packed with 7- $\mu \mathrm{m}$ PFG particles, and $1000 \AA$ and $100 \AA$ pore size, with the dimension of the columns being $8 \mathrm{~mm} \mathrm{ID} \times 300 \mathrm{~mm}$ in length. The mobile phase was a mixture of $\mathrm{HFiP}+0.05 \mathrm{~mol} \mathrm{I}^{-1}$ potassium trifluoroacetate (KTFAc), and flow rate was $1 \mathrm{ml} \mathrm{min}^{-1}$ and injection volume $50 \mu \mathrm{l}$. Detection was performed using a Waters 2414 differential refractive index detector, and data treated with PSS WinGPC unity v7.5 SEC software. The calibration was built using poly(methyl methacrylate) standards supplied by PSS GmbH Mainz, Germany, with molar mass ranging between 800 and 1,600,000 $\mathrm{g} \mathrm{mol}^{-1}$, and the calibration curve was adjusted with an order 5 polynomial. Calculations were conventional, and average molecular weights were expressed in PMMA equivalent.

\section{Results}

\subsection{Mass changes during exposure}

To follow the water concentration during exposure and verify that the hydrolysis process was not controlled by water absorption into the composites and their matrix, mass changes were monitored for all exposure conditions performed in this study. Figures 2, 3, and 4 respectively show sample mass variation during immersion for the 
unfilled PA6.6, the composite with only glass fibers, and the composite containing both glass fibers and elastomer. In all cases, the mass monitoring was carried out at $40^{\circ} \mathrm{C}$, $60^{\circ} \mathrm{C}$, and $80^{\circ} \mathrm{C}$. In all conditions considered here, there was a rapid increase in mass followed by a slight decrease. Let us first focus on the initial increase related to water absorption in the amorphous phase of PA6.6.

It clearly emerges that the water content at saturation in the three materials differed, as the presence of fillers in the composite led to a decrease in water uptake at saturation. As observed for water sorption as a function of water activity in Figure 1, this behavior was induced by the fact that the fillers did not absorb water or at least much less than PA6.6 did, as shown in Table 2.

\begin{tabular}{c|c|c} 
Sample type & Experimental water & Time for saturation (days) \\
& content at saturation (\%) & \\
\hline Unfilled PA6.6 & 8.0 & 3 \\
\hline PA6.6 / glass fibers & 5.6 & 10 \\
\hline PA6.6 / glass fibers & 4.4 & 10 \\
and rubber & &
\end{tabular}

Table 2: Characteristics of water absorption at $80^{\circ} \mathrm{C}$ for the three materials

For longer immersion times, a decrease in mass was observed, with this decrease probably due to the degradation of the material. Indeed, the observed mass drop was often associated with the hydrolysis process, leading to the extraction of shorter 
chains following the chain scission process [18]. This behavior was observed for the three considered materials and was thermally activated. Since a plateau was not evidenced, a water diffusion coefficient assessment based on these results was highly questionable.

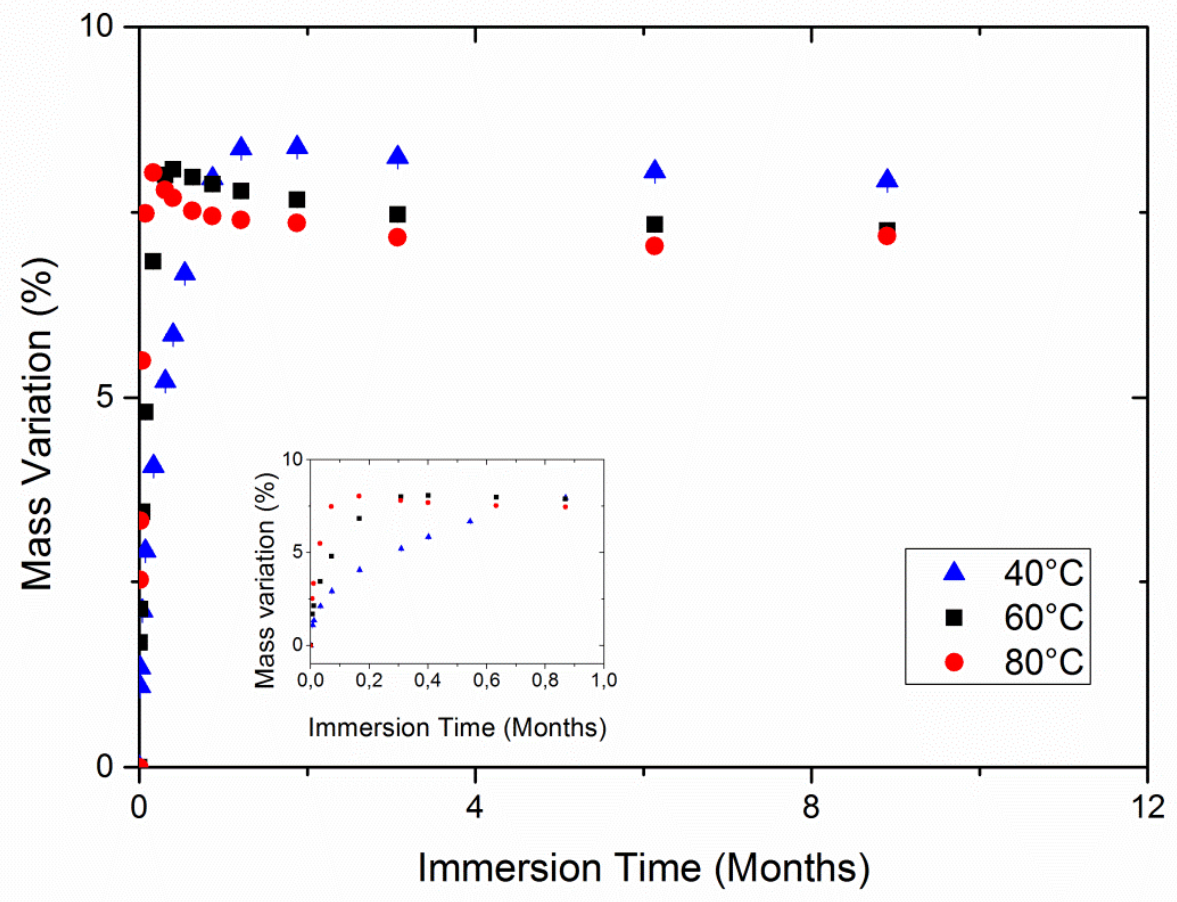

Figure 2: Changes in mass as a function of immersion time in water at $40^{\circ} \mathrm{C}, 60^{\circ} \mathrm{C}$, and $80^{\circ} \mathrm{C}$ for unfilled PA6.6 


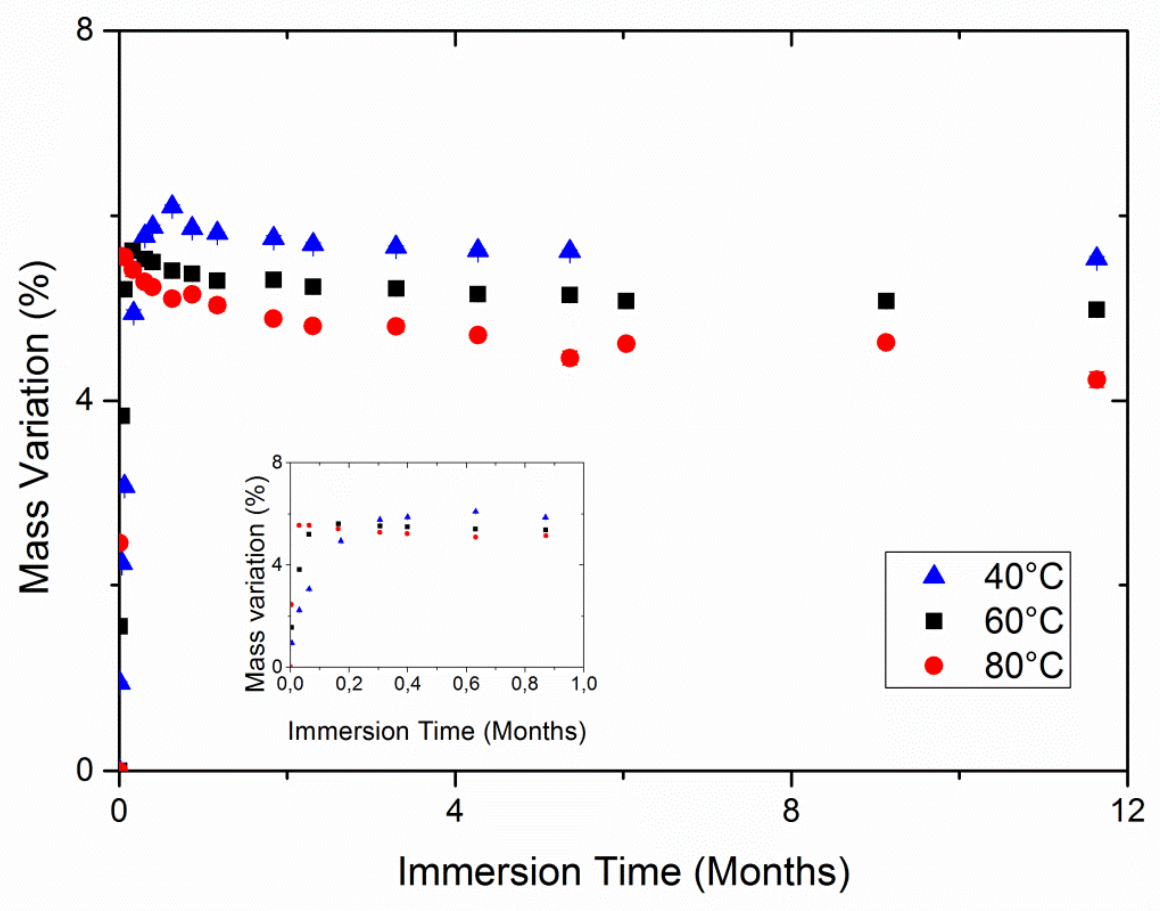

Figure 3: Changes in mass as a function of immersion time in water at $40^{\circ} \mathrm{C}, 60^{\circ} \mathrm{C}$, and $80^{\circ} \mathrm{C}$ for PA6.6 filled with glass fibers 


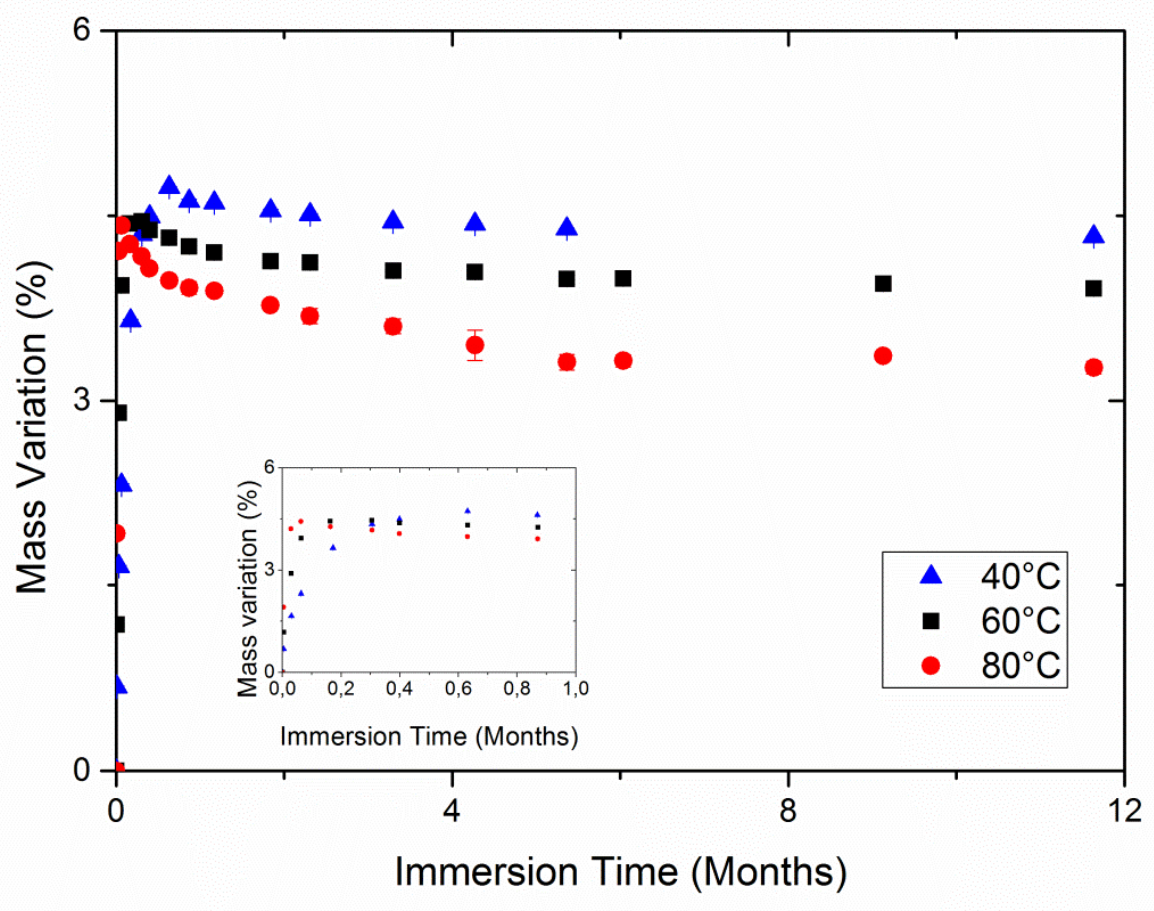

Figure 4: Changes in mass as a function of immersion time in water at $40^{\circ} \mathrm{C}, 60^{\circ} \mathrm{C}$, and $80^{\circ} \mathrm{C}$ for PA6.6 filled with glass fibers and rubber

\subsection{Changes in average molar mass during ageing in water}

Since a chain scission process was expected, molar mass measurements appeared to be the best way to follow macromolecular changes that control mechanical properties. Figure 5 plots changes in average molar mass $\left(M_{n}\right)$ as a function of immersion time at $80^{\circ} \mathrm{C}$ for the three considered materials. For all materials, a decrease in $M_{n}$ was observed during ageing, with this decrease being induced by the chain scission that occurred during the hydrolysis of PA6.6; infrared spectroscopy was used to verify that no oxidation products were visible on the sample surface. The fact that the 
polydispersity index remained stable around 2.5 indicates that this chain scission process can be considered to be a random process, i.e., water diffusion does not limit the hydrolysis rate, as the latter mechanism occurs homogeneously within the materials. It should be noted, however, that the presence of elastomer in the composite containing rubber seems to accelerate the chain scission mechanism. The causes of this slight rate increase may have various origins: for example, filtration of samples during GPC measurements or specific adsorption of long chains on nodules elastomers. For the longest exposure times, $M_{n}$ tends to an asymptotic value close to $10 \mathrm{~kg} \cdot \mathrm{mol}^{-1}$, which could be explained by an equilibrium (amide+water vs acid+amine) associated with the hydrolysis process. Similar values have been found for PA6.6 [19] and PA11 [20].

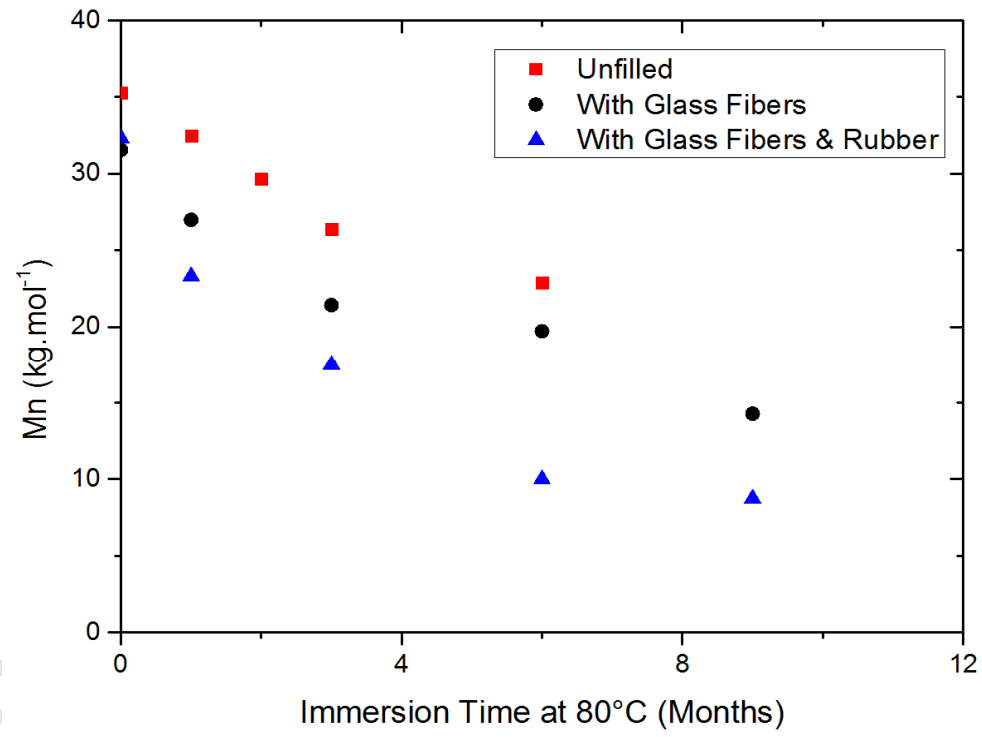

Figure 5: Changes in $\mathrm{Mn}$ as a function of immersion time in water at $80^{\circ} \mathrm{C}$ for unfilled PA6.6, PA6.6 filled with glass fibers, and PA6.6 filled with glass fibers and rubber 
Effect of water temperature during ageing is considered in Figure 6a for PA6.6 filled with glass fibers and in Figure $6 \mathrm{~b}$ for PA6.6 filled with glass fibers and rubber. An increase in water temperature during ageing led to a faster decrease in $M_{n}$, i.e., an increase in the hydrolysis rate (see Discussion section for more details). Simultaneously, an increase in ageing temperature promoted the hydrolysis reaction with respect to condensation, which led to an increase in the molar mass at equilibrium with ageing temperature [21]. In the meantime, polydispersity index (PDI) remains almost constant at 2.3-2.5 up to the brittle behavior as shown in Figure 7. This indicates the chain scission process is randomly distributed in the polyamide matrix. In other words, no specific region of the PA matrix is affected by hydrolysis as, for instance, interphases between fibers and matrix 

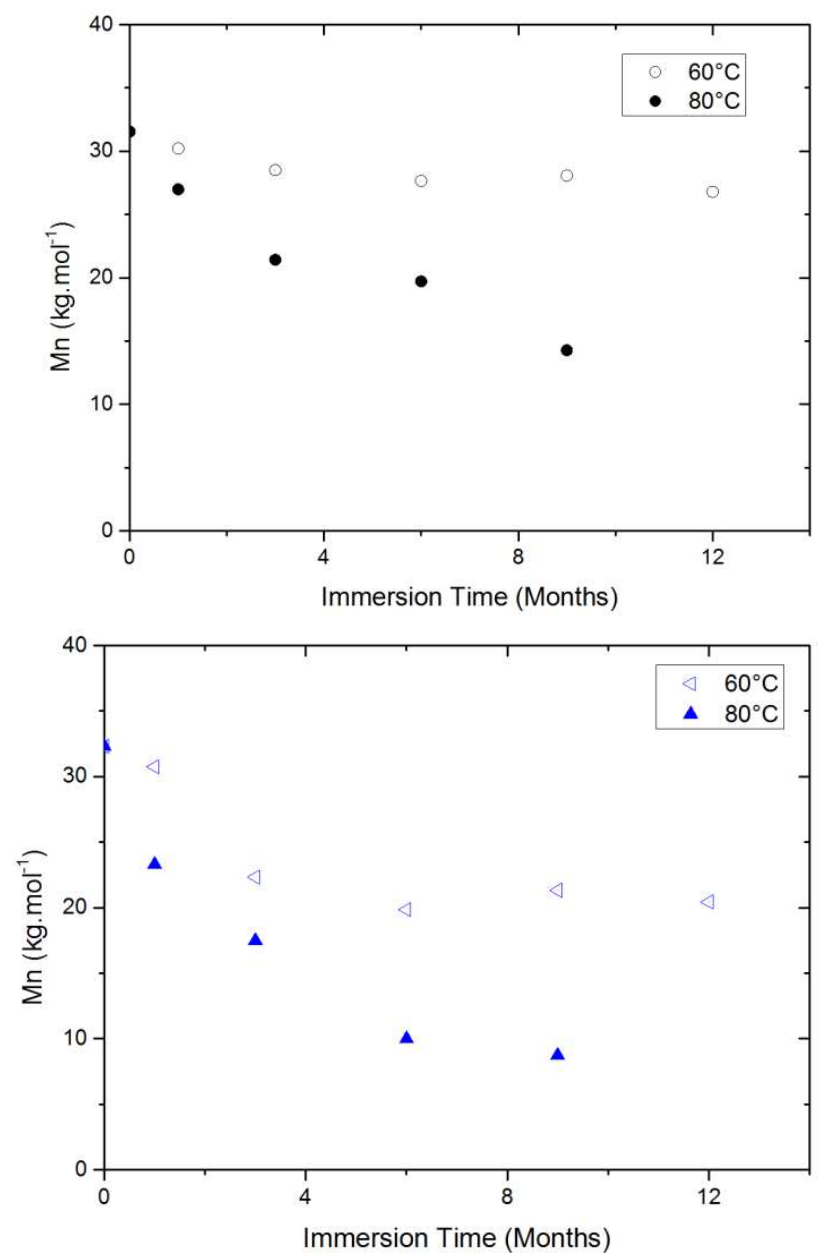

Figure 6: Changes in $\mathrm{M}_{n}$ as a function of immersion time in water at $60^{\circ} \mathrm{C}$ and $80^{\circ} \mathrm{C}$ for PA6.6 filled with glass fibers (above) and PA6.6 filled with glass fibers and rubber (below) 


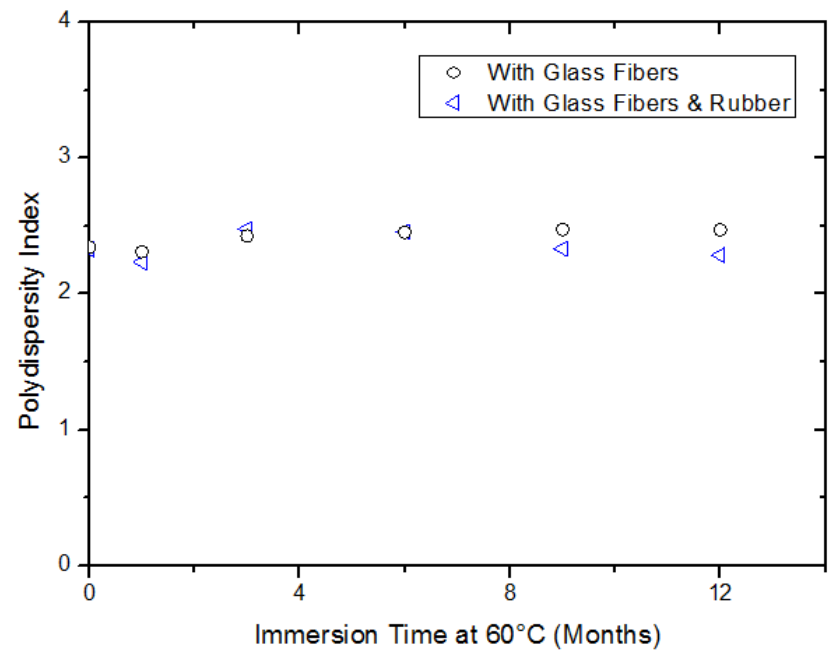

Figure 7: Polydispersity index as function of ageing time at $60^{\circ} \mathrm{C}$ for PA6.6 filled with glass fibers and PA6.6 filled with glass fibers and rubber

\subsection{Impact of the presence of water on tensile behavior without chemical modifications}

We first propose to investigate the impact of water on the mechanical behavior after water saturation but before hydrolysis. This impact is often called "plasticization," since water promotes yield stress decrease by mobility enhancement [22] and can thus modify the embrittlement process that occurs during hydrolysis. For this purpose, tensile behavior was characterized for each material in dry and wet (saturation in water) conditions.

For the PA matrix, the presence of water within PA6.6 led to a large increase in macromolecular mobility and thus changes in tensile behavior. As shown in Figure 8, a large decrease in stiffness as well as yield stress was observed when the unfilled material was fully saturated with water (i.e., with $8.3 \%$ water). Simultaneously, a large 
increase in strain at break was seen. It is noteworthy that this plasticization phenomenon is fully reversible in our case when the polymer is dried.

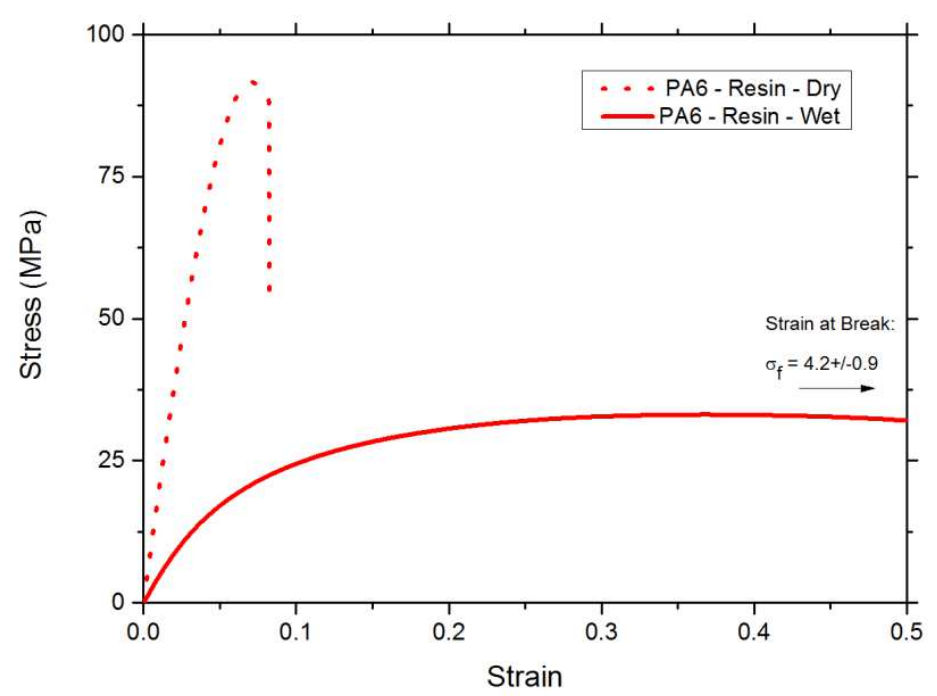

Figure 8: Tensile behavior of unfilled PA6.6 before immersion in water and when fully saturated with no hydrolysis

For both filled composites, the same behavior was observed (Fig. 9), i.e., fully saturated samples showed a lower modulus and higher elongation at break. It is worth noting that the presence of glass fibers led to an increase in modulus compared to the unfilled matrix, as expected. The addition of rubber improved elongation at break (Fig. 9), especially when samples were in wet state. 


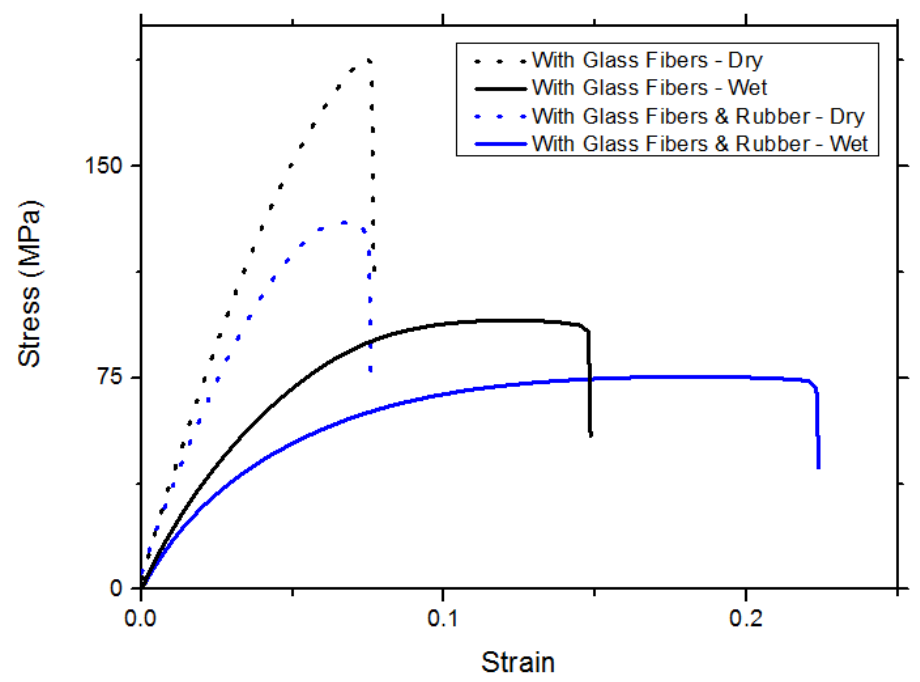

Figure 9: Impact of water absorption in the tensile behavior of PA6.6 filled with glass fibers and PA6.6 filled with both glass fibers and rubber

\subsection{Impact of hydrolysis on tensile behavior in wet state}

Hydrolysis of amide groups led to chain scissions in the macromolecular network that impacted the mechanical behavior of the polymer. Figure 10 presents changes in the tensile behavior of unfilled PA6.6 as a function of ageing time tested in wet conditions. It clearly appears that the behavior is modified after 3 months of immersion in water at $80^{\circ} \mathrm{C}$ : it is noteworthy that if the yield stress remains unchanged, then the strainhardening process occurring after $200 \%$ strain is removed. As a result, only stress and strain at break values drop significantly, whereas properties at low deformation are unmodified. After 6 months of exposure, if the modulus remains constant, no more plastic deformation is observed, indicating a pure brittle behavior. The fact that only fracture properties are impacted by a chain scission mechanism clearly indicates that plastic deformation mechanisms are dependent on molar mass changes. 


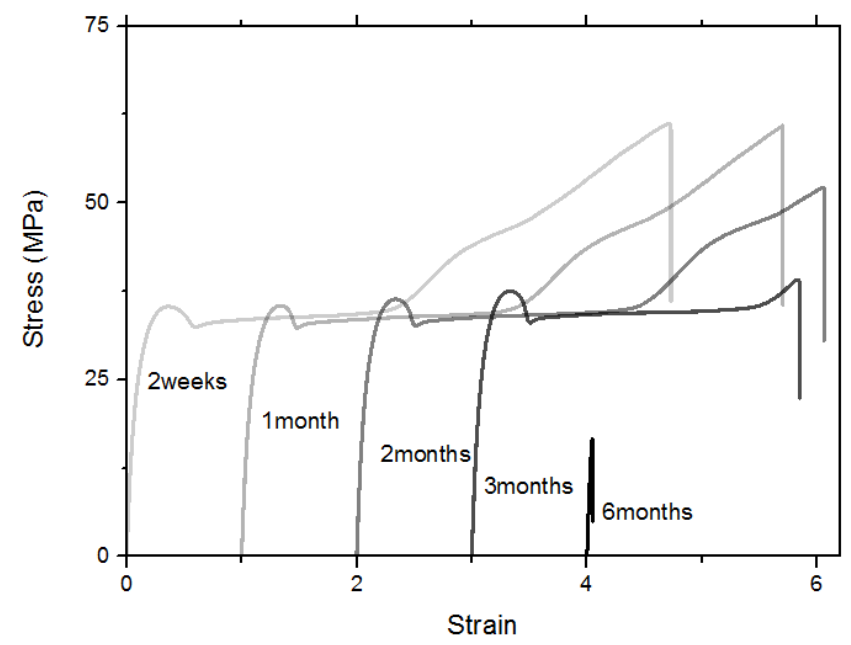

Figure 10: Tensile behavior of unfilled PA6.6 as a function of ageing time in water at $80^{\circ} \mathrm{C}$, tested in wet conditions

In the case of PA6.6 filled with short glass fibers (Fig. 11), exposure in water led to a gradual decrease in strain at break when samples were tested in wet conditions. When rubber was added to the formulation (Fig. 12), the initial strain at break was higher compared to the PA6.6 with only glass fibers, with a decrease also being observed during ageing. As observed, the modulus was not impacted by the degradation for the unfilled PA6.6 as well as the composites, which means that the interfacial cohesion between matrix and fibers was not significantly modified, whereas the matrix plastic deformation was drastically reduced.

To put in evidence the embrittlement kinetic for our three materials, changes in strain at break during ageing in water at $80^{\circ} \mathrm{C}$ are reported in Figure 13 , since strain at break is the most relevant parameter to characterize embrittlement induced by chemical degradation. It appears that regardless of the material, the embrittlement process occurs from the beginning of exposure. However, between 3 and 6 months of 
exposure, unfilled PA6.6 showed a catastrophic drop leading to fully brittle behavior, while the composites showed a more gradual decrease. After 6 months of exposure, strain at break for the unfilled PA was around 5\% despite an initial value close to $400 \%$, whereas the composite exhibited a strain at break close to $7-8 \%$ (initial value of $17 \%$ and $12 \%$ for the filled PA with and without rubber, respectively). In other words, if the fillers clearly modify strain at break before degradation, their effect on strain at break is increasingly insignificant when the PA matrix is strongly degraded.

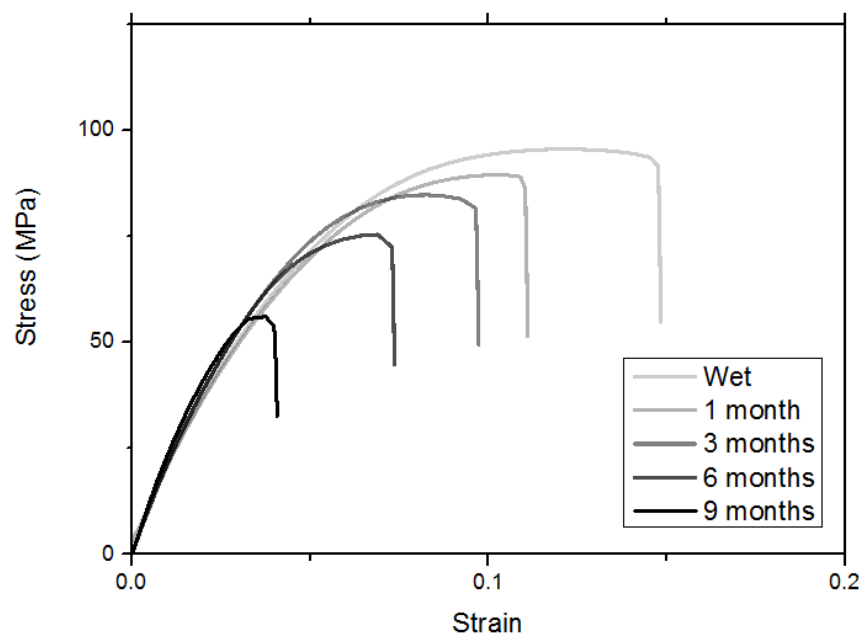

Figure 11: Tensile behavior of PA6.6 filled with glass fibers as a function of ageing time in water at $80^{\circ} \mathrm{C}$, tested in wet conditions 


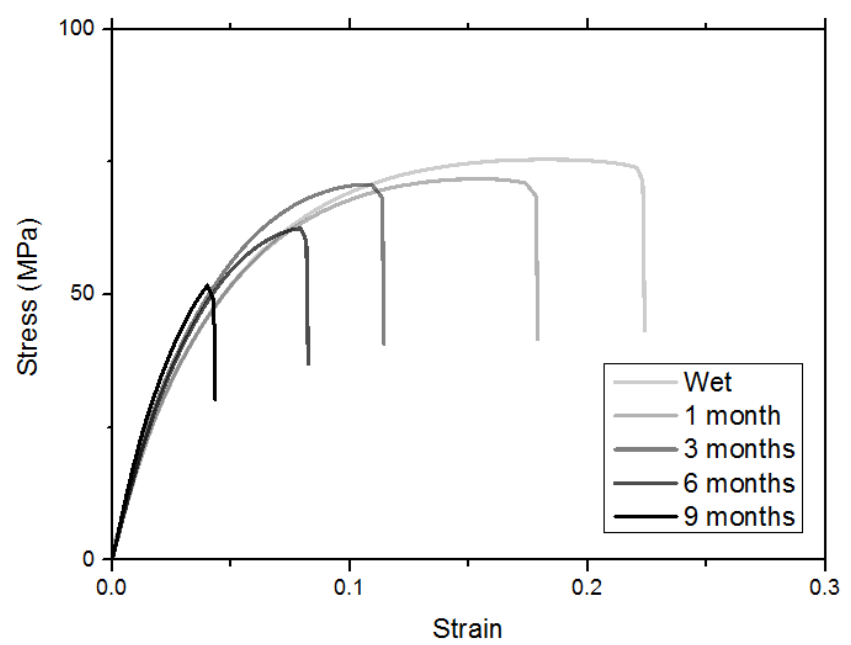

Figure 12: Tensile behavior of PA6.6 filled with short glass fibers and rubber as a function of ageing time in water at $80^{\circ} \mathrm{C}$, tested in wet conditions

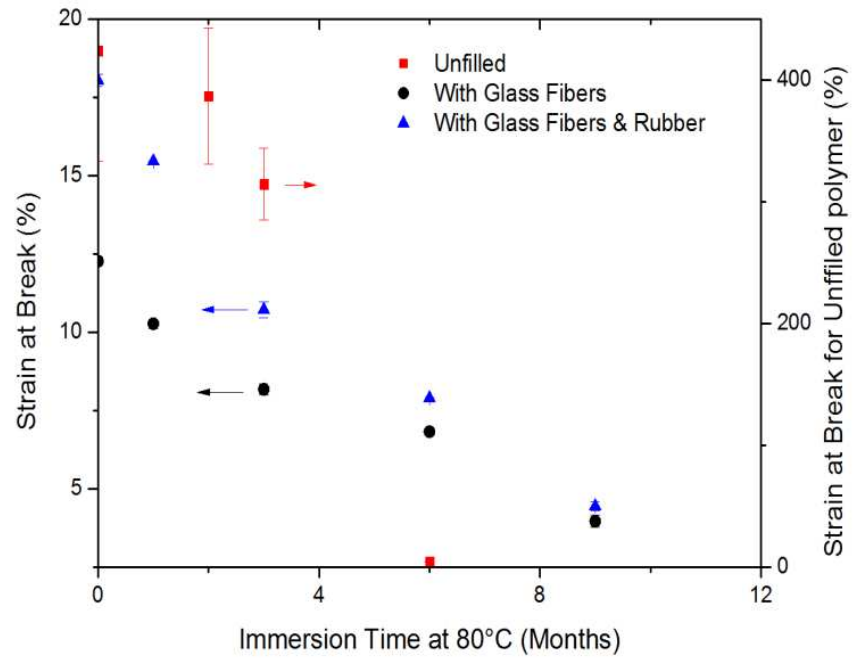

Figure 13: Impact of PA6.6 fillers on the decrease in strain at break during degradation in water at $80^{\circ} \mathrm{C}$, tested in wet conditions

\subsection{Impact of hydrolysis on tensile behavior in dry state}


Similarly to the samples fully saturated by water (see the previous section), tensile behavior was considered with dried samples for different ageing times. Results obtained for PA6.6 filled with both glass fibers and rubber are plotted in Figure 14. As expected, the degradation that occurs in the filled PA6.6 when immersed in water was irreversible, and once again, a decrease in strain at break during ageing occurred.

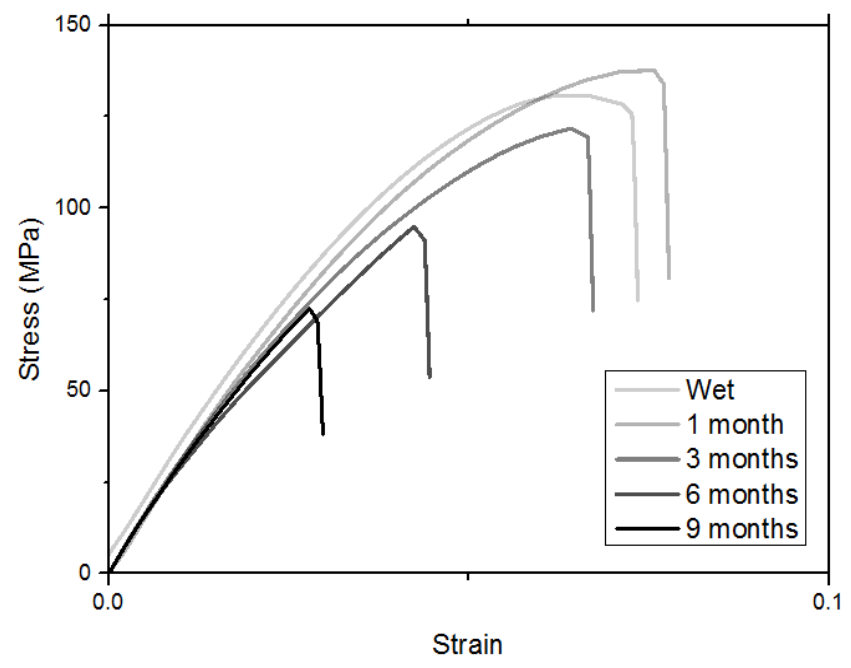

Figure 14: Tensile behavior of PA6.6 filled with short glass fibers and rubber as a function of ageing time in water at $80^{\circ} \mathrm{C}$, tested after drying

\section{Discussion}

\subsection{Assessment of composite embrittlement time}

From a practical perspective, "material lifetime" or "embrittlement time" during ageing is often assessed by considering the decay of strain at break [23]. This approach appears to be valid here, since the strain at break values are the most sensitive 
parameter to detect the embrittlement process compared to stress at break or modulus. For instance, time to embrittlement can be associated with a $50 \%$ drop in the initial value for a given material or with the exposure time when strain at break is below a critical value, with the latter being governed by the part design. For these reasons, we propose in Figure 15 to plot the decrease in strain at break as a function of ageing time for the two composites tested directly with and without drying after ageing. For wet conditions in Figure 15, if we consider the $50 \%$ drop criterion, the embrittlement time is around 6 days for both materials, whereas by considering a critical value of $7.5 \%$, the embrittlement times are 4 and 6 days for the filled PA6.6 with and without rubber, respectively. By using this last criterion, the advantage of the rubber addition can be observed in terms of material lifetime, although the kinetics of the molar mass drop are similar for both composites (Figure 5). Nevertheless, we can note that the use of the $50 \%$ drop criterion can result in the same embrittlement time, notably 6 days, in wet and dry conditions for both materials. 

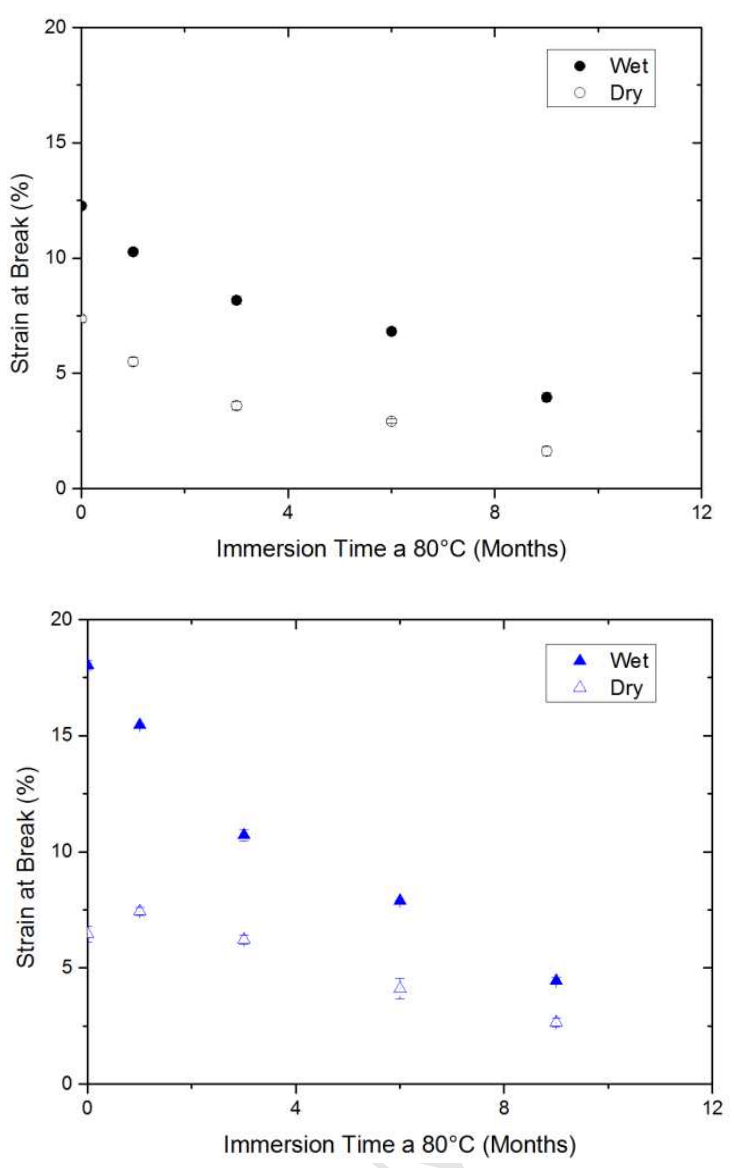

Figure 15: Decrease in stain at break induced by hydrolysis when samples are tested before and after drying for PA6.6 filled with glass fiber (above) and PA6.6 filled with glass fibers and rubber (below).

\subsection{Embrittlement mechanisms for polyamide}

Hydrolysis led to chain scission in the macromolecular network of the resin, which affected the ultimate properties of the PA6.6-based material. This sections aims to discuss the link between $M_{n}$, which characterizes macromolecule length, and strain at break considered to be the ultimate property. As shown previously, the change in 
strain at break emerged as the most relevant parameter to follow the embrittlement process.

By combining Figures 5 and 13 for unfilled material, as expected, a sharp transition from ductile to brittle behavior occurred for a $M_{n}$ of about $25 \mathrm{~kg} / \mathrm{mol}$. This value of $\mathrm{M}_{\mathrm{C}}$ is in accordance with existing values in the literature for PA6 and PA6.6 regardless of whether the chain scission process is due to oxidation [24,25] or hydrolysis [19]. It is worth noting that the value of $\mathrm{M}_{\mathrm{C}}$ can be correlated in a first approach to the molar mass between entanglements $\mathrm{M}_{C}{ }_{C}=5 \mathrm{M}_{\mathrm{e}}$, with $\mathrm{M}_{\mathrm{e}}$ molar mass between entanglements [26]. From a macromolecular point of view, embrittlement occurring when $M_{n}<M_{C}^{\prime}$ is associated with the loss of capacity to stretch the entanglement networks, since the chain disentanglements can more easily occur. From the perspective of deformation mechanisms, $\mathrm{M}_{\mathrm{C}}$ can result from a competition between plastic deformation and cavitation that occurs during the tensile test. Below $\mathrm{M}_{\mathrm{C}}$, a cavitation process and thus brittle failure is promoted, whereas plastic deformation and thus ductility occurs above $\mathrm{M}^{\prime}{ }_{\mathrm{C}}$. By considering the last issue, $\mathrm{M}^{\prime}{ }_{\mathrm{C}}$ value should be dependent on temperature/strain rate/water content as well as the stress-strain field occurring during the mechanical test. For PA11 where chain scission is induced by oxidation, it has been shown that $\mathrm{M}^{\prime}{ }_{\mathrm{C}}$ decreases when the tensile test temperature increases [27].

\subsection{Failure mechanisms for composites}

Let us first consider the composite materials before degradation. Compared to the matrix behavior, the initial behavior is largely affected by fillers as expected. If the 
modulus increases sharply with fibers, failure properties are largely modified. For instance, strain at break values drop from $400 \%$ to $12.5 \%$ in wet conditions (Fig. 12). These consequences of fiber incorporation are often attributed to completely different failure mechanisms such as fiber fracture, fiber pullout, fiber/matrix debonding, and micro-ductile matrix deformation [28]. It is clear that fibers modify the stress state of the matrix, since hydrostatic stress and thus cavitation are promoted, especially when fibers are relatively close to each other [29].

When comparing wet and dry conditions (Fig. 15), the discrepancy of strain at break values before degradation ( $12.5 \%$ vs $7.5 \%$ ) can be attributed to the well-known polyamide plasticization effect. In terms of deformation mechanisms, wet conditions promote an increase in density and volume of matrix damage such as cavitation and fibrillation for a given fiber orientation [30]. However, it has also been proposed that water content modifies the interfacial properties between fibers and matrix, leading to fiber-matrix debonding [31,32]. As a result, we can assume that water content promotes ductile matrix microcracks and thus higher strain at break values, but it can also initiate specific damage in the interfacial region.

Lastly, by comparing strain at break values with and without rubber particles (Fig. 15), it appears that the rubber addition leads to ductility, especially in wet conditions. Since rubber particles are mainly located in the matrix, the improvement in strain at break is due to improved ductile behavior by limiting microcrack propagation in the matrix. In other words, rubber particles delay damage initiation by reducing the generation of local stress concentration. 


\subsection{Embrittlement mechanisms for composites}

In the previous section, we discussed the different failure mechanisms that occur before degradation. Although interfacial decohesion can be induced by water, we propose in a first approach to consider that the strain at break changes during hydrolysis are mainly governed by the matrix embrittlement, as seen for the pure polyamide in §4.2. For this reason, strain at break values are reported as a function of $M_{n}$ in Figure 17 for the two composites in wet and dry conditions. The choice to correlate failure property changes with $M_{n}$ is proposed since the latter parameter is recognized as the best molar mass parameter compare especially to $M_{w}$ [33].

According to Figure 17a, it appears that the presence of such fibers prevents a sharp decrease in strain at break during hydrolysis. In fact, linear behavior was observed between strain at break and $M_{n}$ values, which are directly related to the extent of the degradation process. Here, results obtained for ageing at $80^{\circ} \mathrm{C}$ and $60^{\circ} \mathrm{C}$ were reported, revealing the existence of a master curve that is independent of ageing temperature.

By applying the same approach to the dry sample, it appears that this behavior is not related to the presence of water within the composite, because strain at break after ageing and drying follow the same trend (Fig. 17b).

In the presence of both glass fibers and rubber, there is likewise no sharp transition. Moreover, there is once again a linear decrease in strain at break in wet state with the $M_{n}$ value. However, for the same value of $M_{n}$, i.e., the same extent of hydrolysis process, strain at break is higher by a factor of 1.5 to 2 . This means that the rubber 
addition allows for a higher value of strain at break; this observation is even more evident when water is removed. In fact, in Figure 17b, we can see that (except for the first point), strain at break in the dried samples with rubber is much higher than in the composite without rubber. Practically, this means that for an application requiring a minimal specific strain at break, rubber can be used to increase the critical $M_{n}$ value. For example, if a critical strain at break of $10 \%$ is required in a wet state, the critical $M_{n}$ value for the PA6.6-based composite without rubber will be $25 \mathrm{~kg} \cdot \mathrm{mol}^{-1}$, whereas this critical value will be around $15 \mathrm{~kg} \cdot \mathrm{mol}^{-1}$ with rubber.
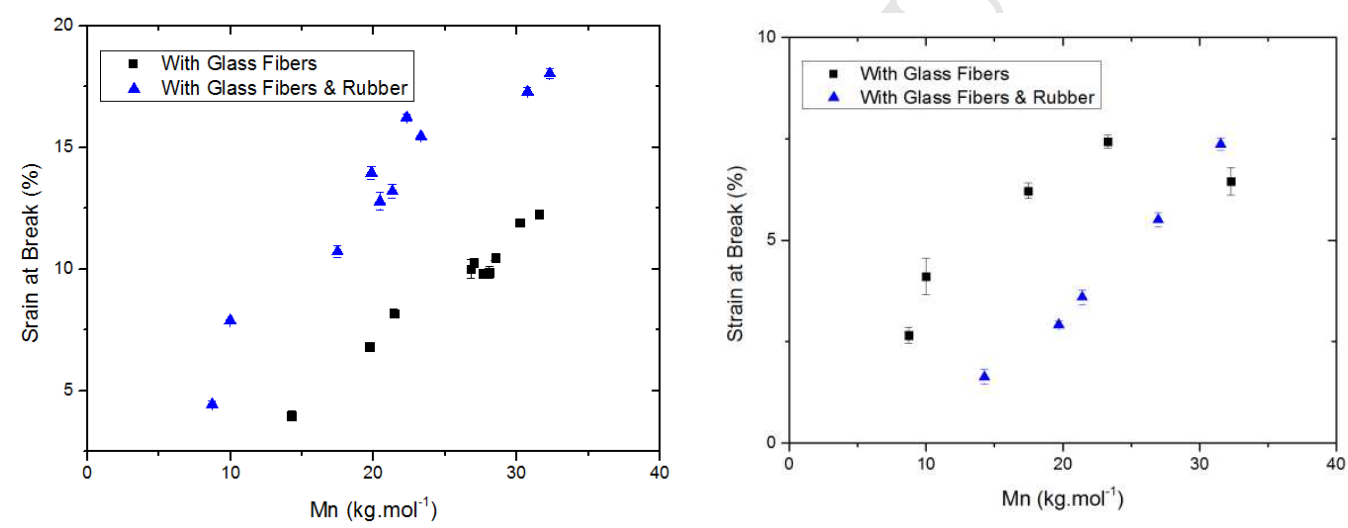

Figure 17: Strain at break as a function of $M_{n}$ in wet (left) and dry states (right)

Given that the strain at break drop appears to be highly connected with the molar mass decrease due to hydrolysis, regardless of the composite or dry/wet condition, we may conclude that the embrittlement mechanism is governed by the matrix behavior and not the interfacial cohesion between fiber and matrix. As it is recognized that molar mass decrease promotes cavitation over plastic deformation, the damage process by hydrolysis could be the following: matrix deformation bands are restricted due to the molar mass decrease by inducing specific damages such as fibrillation and 
cavitation according to the localization of the ductility. Wet conditions or the addition of rubber particles would delay the damage of these mechanisms, leading to a lifetime improvement for a given exposure condition.

\section{Conclusions}

This paper presents a study on the durability of PA6.6-based composites with different types of fillers in a wet environment. Three types of materials are considered here: an unfilled PA6.6, a PA6.6 composite containing $25 \%$ short glass fiber, and a third material with the same amount of fiber and the addition of an elastomer. The three materials were aged in water at $40^{\circ} \mathrm{C}, 60^{\circ} \mathrm{C}$, and $80^{\circ} \mathrm{C}$ and characterized over time with mass monitoring to characterize water absorption. The tensile mechanical properties were considered during ageing in both wet and dry states to highlight the reversible or nonreversible aspect of the degradation. Lastly, molar mass measurements were performed to evaluate the chain scission by hydrolysis in the polyamide.

First, the amount of water absorbed by the material was, as expected, directly related to the amount of fillers in the composite, because water was mainly absorbed by the amorphous phase of PA6.6. The presence of water within the material led to a large plasticization that decreased stiffness and yield stress as well as increased elongation at break for the three considered materials. The use of short glass fibers reduced the decrease in stiffness induced by the presence of water. Furthermore, the use of rubber led to an increase in elongation at break in wet state. 
Second, hydrolysis was studied during ageing. In the presence of water, polyamide underwent a chemical degradation that led to chain scission in the polymer. This chain scission process induced considerable changes in the ultimate properties of the three considered materials. For the pure polyamide, sharp embrittlement occurred when the chain length was low enough to be below a critical value, named $M^{\prime} c$ and found to be close to $20 \mathrm{~kg} \cdot \mathrm{mol}^{-1}$ in this case. This behavior was not found for the two composites, as the decrease in strain at break was linear with $M_{n}$ of the matrix for all ageing temperatures considered here. This means that the use of glass fiber prevented a sharp ductile/brittle transition in the composite. Moreover, when rubber was added to the composite, an increase in strain at break occurred in wet conditions, meaning that for the same $M_{n}$ value (related to the extent of the degradation process), the strain at break was higher with rubber. As a result, we suggest that the embrittlement mechanisms for the composites are mainly governed by the matrix embrittlement coupled with the specific stress state generated by the presence of the fibers and rubber particles.

From a practical point of view, the master curves showing the strain at break for the composite material with the $M_{n}$ value will be very useful for any lifetime prediction in a humid environment when PA6.6-based composites are used, since they are independent of the chain scission kinetic controlled by the exposure temperature.

\section{Acknowledgements}


The authors wish to thank N Lacotte, M Premel Cabic from Ifremer and V Defauchy from PIMM Lab for the performing of tests. 


\section{References}

[1] Sagar BF. Autoxidation of N-alkyl amides. Part III. Mechanism of thermal oxidation. J Chem Soc B 1967:1047-1061.

[2] Richaud E, Diogo O, Fayolle B, Verdu J, Guilment J, Fernagut F. Auto-oxidation of aliphatic polyamides. Polym Degrad Stab 2013;98(9):1929-1939.

[3] Gijsman P, Dong W, Quintana A, Celina M. Influence of temperature and stabilization on oxygen diffusion limited oxidation profiles of polyamide 6. Polym Degrad Stab 2016;130:83-96.

[4] Heikens D, Hermans PH, Veldhoven HA. Kinetics of the acid hydrolysis of cyclic oligomers from nylon 6 and nylon 6.6. Macromol Chem Phys 1959;30(1):154-168.

[5] Arhant M, Le Gac PY, Le Gall M, Burtin C, Briançon C, Davies P. Modelling the non Fickian water absorption in polyamide 6. Polym Degrad Stab 2016;133:404-412.

[6] Le Gac PY, Arhant M, Le Gall M, Davies P. Yield stress changes induced by water in polyamide 6: characterization and modeling. Polym Degrad Stab 2017;137:272-280.

[7] Silva L, Tognana S, Salgueiro W. Study of the water absorption and its influence on the Young's modulus in a commercial polyamide. Polym Test 2013;32(1):158-164.

[8] Chaupart N, Serpe G, Verdu J. Molecular weight distribution and mass changes during polyamide hydrolysis. Polym 1998;39(6-7):1375-1380.

[9] Fayolle B, Richaud E, Colin X, Verdu J. Degradation-induced embrittlement in semi-crystalline polymers having their amorphous phase in rubbery state. J Mater Sci 2008;43(22):6999-7012.

[10] Curtis PT, Bader MG, Bailey JE. The stiffness and strength of a polyamide thermoplastic reinforced with glass and carbon fibres. J Mater Sci 1978;13(2):377-390.

[11] Leach DC, Moore DR. Failure and fracture of short glass fibre-reinforced nylon composites.Compos $1985 ; 16(2): 113-120$. 
[12] Launay A, Maitournam MH, Marco Y, Raoult I. Multiaxial fatigue models for short glass fiber reinforced polyamide-Part I: Nonlinear anisotropic constitutive behavior for cyclic response. Int J Fatigue 2013;47:382-389.

[13] Laura DM, Keskkula H, Barlow JW, Paul DR. Effect of glass fiber and maleated ethylene-propylene rubber content on the impact fracture parameters of nylon 6 Polym 2001 42(14): 6161-6172.

[14] Broudin M, Le Saux V, Le Gac PY, Champy C, Robert G, Charrier P, Marco Y. Moisture sorption in polyamide 6.6: Experimental investigation and comparison to four physical-based models. Polym Test $2015 ; 43: 10-20$.

[15] Bernstein R, Gillen KT. Nylon 6.6 accelerating aging studies: II. Long-term thermal-oxidative and hydrolysis results. Polym Degrad Stab 2010;95(9):1471-1479.

[16] Laun S, Pasch H, Longiéras N, Degoulet C. Molar mass analysis of polyamides-11 and-12 by size exclusion chromatography in HFiP. Polym 2008;49(21):4502-4509.

[17] Okamba-Diogo O, Richaud E, Verdu J, Fernagut F, Guilment J, Fayolle B. Molecular and macromolecular structure changes in polyamide 11 during thermal oxidation-Kinetic modeling. Polym Degrad Stab 2015;120:76-87.

[18] Shanahan MER, Auriac Y. Water absorption and leaching effects in cellulose diacetate. Polym 1998;39(5):1155-1164.

[19] El-Mazry C, Correc O, Colin X. A new kinetic model for predicting polyamide 6-6 hydrolysis and its mechanical embrittlement. Polym Degrad Stab 2012;97:1049-1059.

[20] Meyer A, Jones N, Lin Y, Kranbuehl D. Characterizing and modeling the hydrolysis of polyamide-11 in a pH 7 water environment. Macromol 2002;35(7):2784-2798.

[21] Jacques B, Werth M, Merdas I, Thominette F, Verdu J. Hydrolytic ageing of polyamide 11. 1. Hydrolysis kinetics in water. Polym 2002;43(24):6439-6447. 
[22] Valentin D, Paray F, Guetta B. The hygrothermal behaviour of glass fibre reinforced PA66 composites: A study of the effect of water absorption on their mechanical properties. J Mater Sci 1987;22(1):46-56

[23] Celina MC. Review of polymer oxidation and its relationship with materials performance and lifetime prediction. Polym Degrad Stab 2013;98(12):2419-2429.

[24] Dong W, Gijsman P. Influence of temperature on the thermo-oxidative degradation of polyamide 6 films. Polym Degrad Stab 2010;95(6):1054-1062.

[25] Forsström D, Terselius B. Thermo oxidative stability of polyamide 6 films I. Mechanical and chemical characterisation. Polym Degrad Stab 2000;67(1):69-78.

[26] Creton C, Kramer EJ, Brown HR, Hui CY. Adhesion and fracture of interfaces between immiscible polymers: from the molecular to the continuum scal. In Molecular Simulation Fracture Gel Theory. Berlin, Heidelberg: Springer, 2001. p. 53-136.

[27] Okamba-Diogo O, Richaud E, Verdu J, Fernagut F, Guilment J, Fayolle B. Investigation of polyamide 11 embrittlement during oxidative degradation. Polym 2016;82:49-56.

[28] Karger-Kocsis J, Friedrich K. Fracture behavior of injection-molded short and long glass fiberpolyamide 6.6 composites. Compos Sci Techn 1988;32(4):293-325.

[29] Sato N, Kurauchi T, Sato S, Kamigaito O. Microfailure behaviour of randomly dispersed short fibre reinforced thermoplastic composites obtained by direct SEM observation. J Mater Sci 1991;26(14):38913898.

[30] Rolland H, Saintier N, Wilson P, Merzeau J, Robert G. In situ X-ray tomography investigation on damage mechanisms in short glass fibre reinforced thermoplastics: Effects of fibre orientation and relative humidity. Composites Part B 2017;109:170-186.

[31] Bergeret A, Ferry L, lenny P. Influence of the fibre/matrix interface on ageing mechanisms of glass fibre reinforced thermoplastic composites (PA-6, 6, PET, PBT) in a hygrothermal environment. Polym Degrad Stab 2009;94(9):1315-1324. 
[32] Arif MF, Meraghni F, Chemisky Y, Despringre N, Robert G. In situ damage mechanisms investigation of PA66/GF30 composite: Effect of relative humidity. Composites Part B 2014;58:487-495.

[33] Dai CA, Kramer EJ, Washiyama J, Hui CY. Fracture toughness of polymer interface reinforced with diblock copolymer: effect of homopolymer molecular weight. Macromolecules 1996;29(23): 7536-43. 